\title{
Rain-flagging of the Envisat altimeter
}

\author{
Graham D. Quartly \& Meric A. Srokosz \\ Laboratory for Satellite Oceanography \\ Southampton Oceanography Centre \\ Southampton, UK \\ <gdq@soc.soton.ac.uk>
}

\begin{abstract}
As the goals for altimetric measurements become ever more precise, there is concern about the reliable detection and discarding of rain contaminated data. A dual-frequency rain detection technique developed for the $\mathrm{K}_{\mathrm{u}^{-}}$and $\mathrm{C}$-band TOPEX altimeter, is adapted for the $K_{u^{-}}$and S-band RA-2 altimeter on Envisat. Of particular concern is the selection of a suitable threshold to minimise the quantity of good data inadvertently discarded.
\end{abstract}

Keywords - dual-frequency altimetry; Envisat RA-2; rainflagging; attenuation

\section{INTRODUCTION}

Over the sea surface the radar altimeter echo has a welldefined shape, enabling sea surface height (ssh) and wave height $\left(\mathrm{H}_{\mathrm{s}}\right)$ to be determined accurately by fitting to an expected shape for the return. If there are rain cells in part of the altimetric footprint then the return waveform is not 'oceanlike' and the quality of the derived geophysical information is degraded [1]. Thus a key aspect of quality control is the reliable detection of rain-affected data. The microwave radiometer (MWR) provides some information on rain, but its footprint is much larger than typical rain cells leading to too many points being flagged. A dual-frequency detection technique works well for TOPEX [2-5]. It relies on the normally close relationship in normalised backscatter $\left(\sigma^{0}\right)$ at the two frequencies, with significant departures $\left(\sigma_{\mathrm{Ku}}^{0}\right.$ lower than expected) being attributed to rain. The backbone of such a method for the $\mathrm{K}_{\mathrm{u}}$ - and S-band frequencies of the Envisat RA-2 altimeter is shown in Fig. 1. There is very good agreement between the backscatter at the two frequencies, especially for moderate winds $\left(>3 \mathrm{~ms}^{-1}\right)$. The mean difference between $\sigma_{\mathrm{Ku}}^{0}$ and $\sigma_{\mathrm{S}}^{0}$ (Fig. 1b) shows a peak at $\sigma_{\mathrm{S}}^{0}=10.7 \mathrm{~dB}\left(\sigma_{\mathrm{Ku}}^{0}=11.5\right.$ $\mathrm{dB})$, corresponding to a wind speed of $7 \mathrm{~ms}^{-1}$. The scatter about this mean relationship is very small (std. dev. of less than 0.25 $\mathrm{dB}$ ) for $\sigma_{\mathrm{S}}^{0}<12.3 \mathrm{~dB}$, but in low wind conditions there is much poorer agreement between the values at the two frequencies (for reasons that are not well understood). Note, the vast majority of points correspond to $\sigma_{\mathrm{S}}^{0}<15 \mathrm{~dB}$ (wind speeds greater than $\left.1 \mathrm{~ms}^{-1}\right)$. The shape of the mean difference and std. dev. curves (Figs. 1b,c) for low wind speeds are less well-defined, and depend on the choice of data editing criteria.

\section{NORTH PACIFIC CASE STUDY}

Fig. 2 shows Envisat over-flying an intense rain cell north of Hawaii. The top panels show the $18 \mathrm{~Hz}$ average waveforms. At the start of the transit at $29.1^{\circ} \mathrm{N}$ both frequencies display
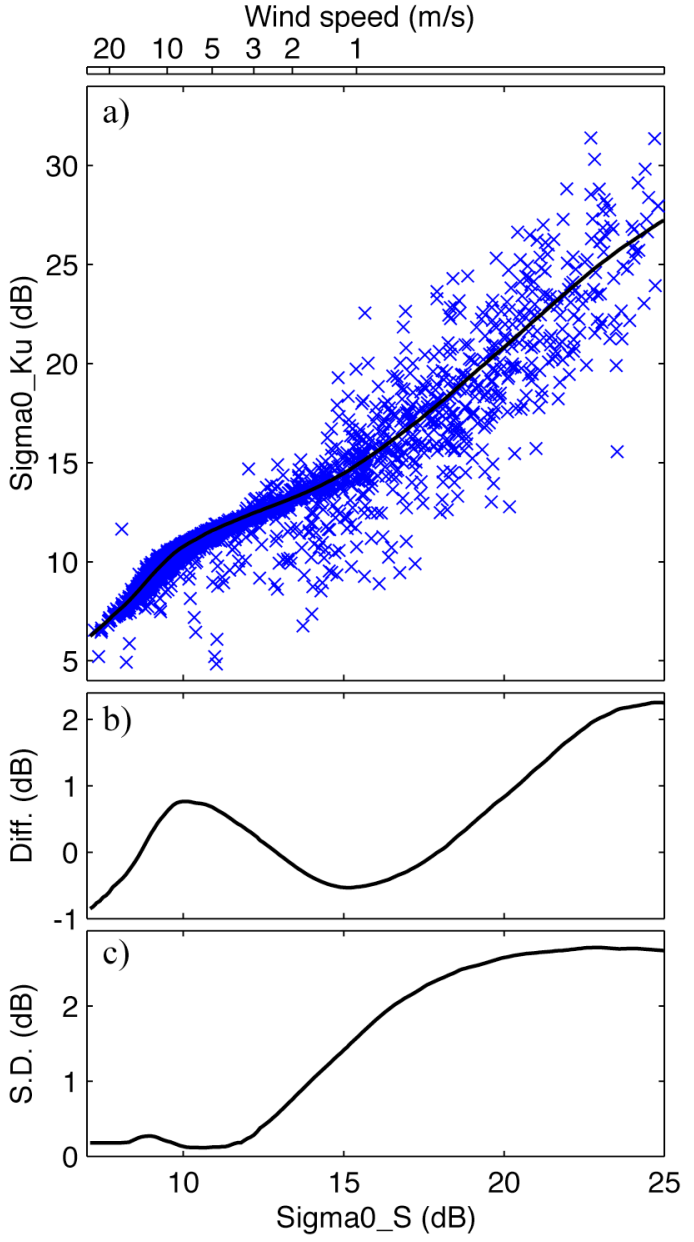

Figure 1. a) Scatter plot of normalized backscatter $\left(\sigma^{0}\right)$ at $\mathrm{K}_{\mathrm{u}^{-}}$and S-band. Black line shows the mean relationship. b) Mean relationship expressed as difference in $\sigma^{0}$ values. c) Scatter in observations.

typical ocean-like returns - an initial region of near-zero value, a sharp 'leading edge' near bin 48 , with a peak shortly after, and a gradual reduction along the 'trailing edge'. Nearing $29.7^{\circ} \mathrm{N}$ the strength of the $\mathrm{K}_{\mathrm{u}}$-band signal reduces (Fig. $2 \mathrm{c}$ ), although the waveform values (Fig. 2b) are maintained by the response of the Automatic Gain Control (AGC). The S-band $\sigma^{0}$ remains $\sim 9 \mathrm{~dB}$ across the transect. The $\mathrm{S}$-band waveform amplitude rises to 950 counts (Fig. 2a), 10 times that outside the rain cell, but this is purely due to the AGC compensation for the $10 \mathrm{~dB}$ of $\mathrm{K}_{\mathrm{u}}$-band attenuation. Similarly, the abrupt 
movement of the S-band leading edge at $29.9^{\circ} \mathrm{N}$ is due to its on-board tracker being slaved to the $\mathrm{K}_{\mathrm{u}}$-band one. Small welldefined rain cells give a distinctive parabolic attenuation pattern, from which their location, size and intensity may be deduced [6,7]. Here there are a number of features, so it is the heightened values (indicating an absence of rain) that are prominent in Fig. 2b. When the major attenuation features get to the leading edge, the waveform shape is so affected that the derived estimates of ssh and $\mathrm{H}_{\mathrm{s}}$ (Fig. 2d,e) show a sharp change, with increased uncertainties in these estimates. The detection of a rain event is confirmed by the 2-channel MWR (Fig. 2f), although that instrument has a much larger footprint.

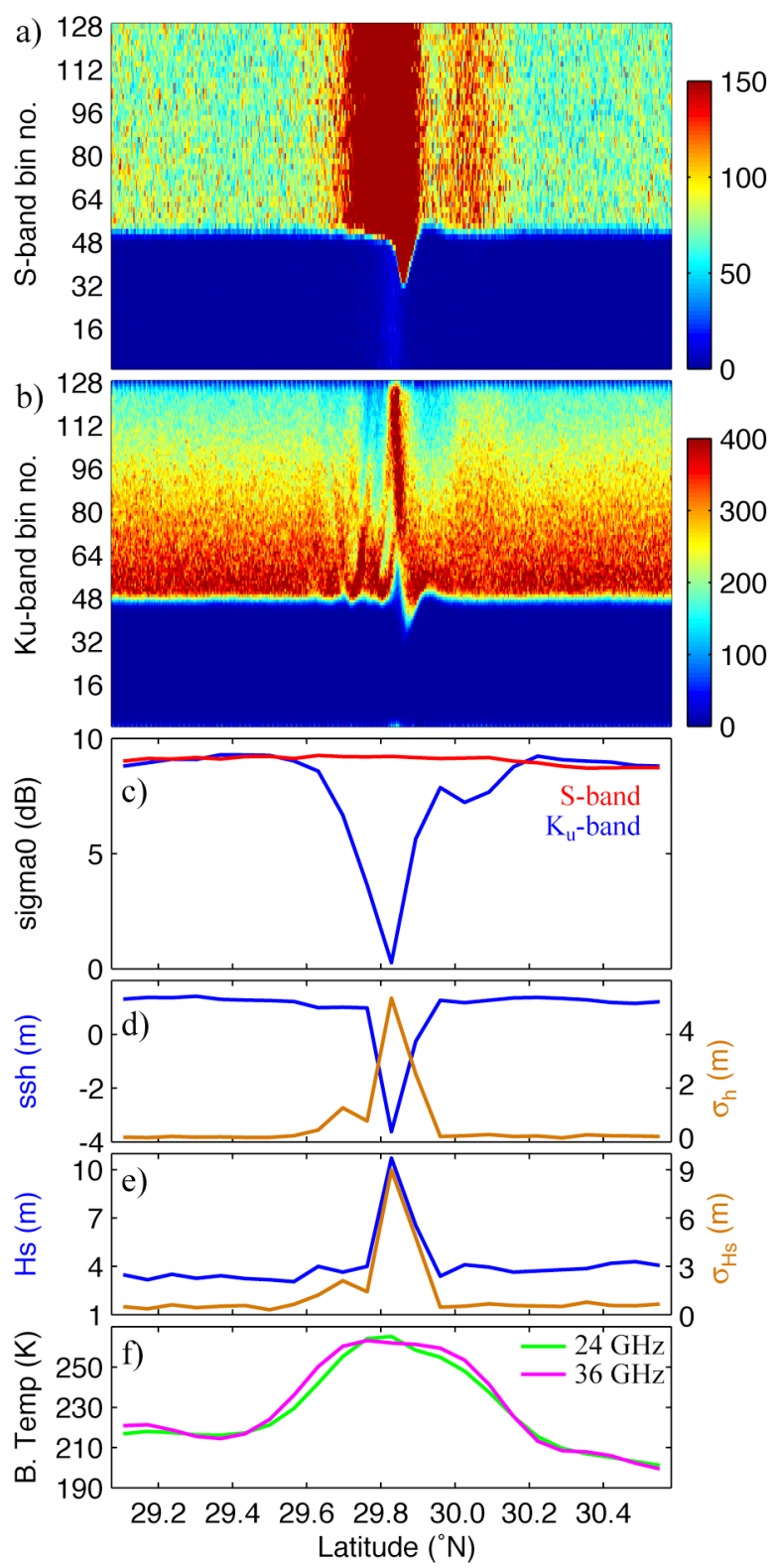

Figure 2. Envisat data for a transit across an intense rain cell in N. Pacific. Waveform data in top two panels are expressed in counts. (ssh - sea surface height; $\mathrm{H}_{\mathrm{s}}-$ wave height; $\sigma_{\mathrm{h}}, \sigma_{\mathrm{Hs}}-$ uncertainty in ssh and $\mathrm{H}_{\mathrm{s}}$; B. Temp Brightness temperature from MWR.)

\section{THRESHOLD FOR RAIN DETECTION}

Fig. 2 demonstrates most of the possible effects of intense rain at nadir, and such bad data are easily recognised and discarded by any of a number of tests (spikes in ssh or $\mathrm{H}_{\mathrm{s}}$, large values of $\sigma_{\mathrm{h}}$ or $\sigma_{\mathrm{Hs}}$, and high MWR atmospheric liquid water content). A greater challenge is the reliable detection of much smaller (but more frequent) events that cause smaller changes in the observations. The $\mathrm{K}_{\mathrm{u}}$-band attenuation has been shown to be a good indicator for TOPEX data, either used alone [2, 4] or with radiometer data [3]. For TOPEX, a suitable rain-detection threshold was found to be $0.5 \mathrm{~dB}$ or twice the std. dev. For the RA-2 the scatter of points (Fig. 1c) is much greater than for TOPEX. Consequently a $0.5 \mathrm{~dB}$ threshold is not valid across the whole range of $\sigma_{S}^{0}$ values; will a simple multiple of the std. dev. suffice? Fig. 3 gives histograms of the observed attenuation for different $\sigma_{S}^{0}$ ranges (corresponding mainly to different wind conditions). For a logarithmic ordinate scale, a normal distribution (as expected for measurement errors) is displayed as a parabola, and an exponential distribution (similar to observed rainfall rate) as a straight line. The break in slope may act as an indicator of a suitable threshold, accepting that some points from the rain distribution lie to the right of it, and some 'measurement error' points lie to the left. For Figs. 3a,b such a 'break point' corresponds to more than 2 std. dev. from the mean, whilst in lower wind conditions (Figs $3 \mathrm{c}, \mathrm{d})$ the choice of threshold is less clear. In Figs. 3a-c, almost all of the points with an attenuation of $1 \mathrm{~dB}$ or more are also flagged by a simple MWR test. However, there are marked differences between the plots as each preferentially selects from different latitudinal bands, according to the associated wind conditions, and the resultant distributions may reflect differences in rain rate statistics for stratiform and convective rain cells. The distribution in Fig. 3d has a large tail for positive $\Delta \sigma^{0}$, corresponding to $\sigma_{\mathrm{Ku}}^{0}$ higher than expected according to $\sigma_{S}^{0}$; further examination is required to see whether these are due to isolated points or large-scale 'sigma0 blooms'.

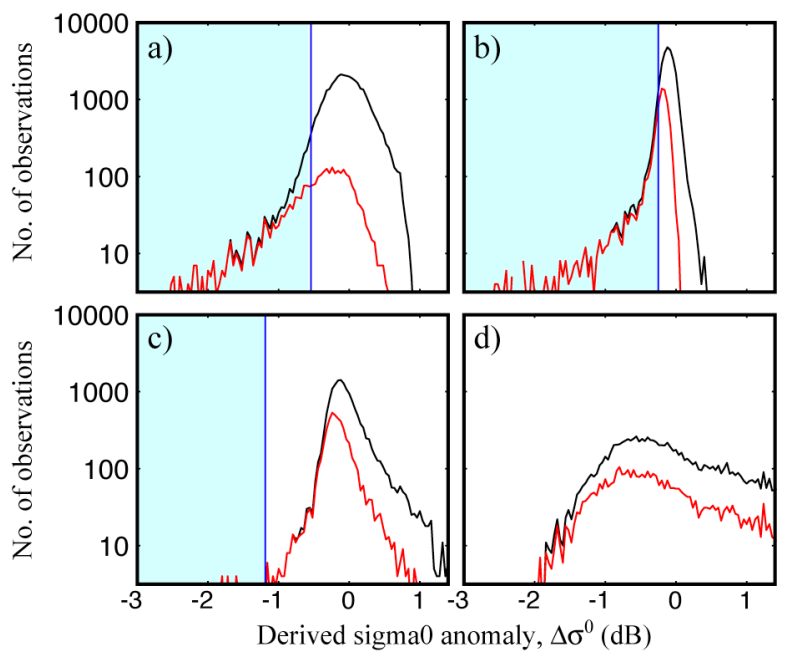

Figure 3. Histograms of $\Delta \tilde{\sigma}$ (values less than zero correspond to attenuation); a) $\sigma_{S}^{0}=9 \mathrm{~dB}$, b) $\sigma_{S}^{0}=11 \mathrm{~dB}$, c) $\sigma_{S}^{0}=13 \mathrm{~dB}$, d) $\sigma_{S}^{0}=16 \mathrm{~dB}$. (Black line corresponds to all data, red line to those which also have $\mathrm{BT}_{24}>200 \mathrm{~K}$; blue region represents those data discarded according to a threshold of 2 std. dev.) 


\section{SUMMARY}

Rain attenuation of the RA-2 $\mathrm{K}_{\mathrm{u}}$-band is as expected from models and TOPEX analysis, with intense rain affecting all geophysical parameters. S-band is not affected by rain; but in the case study, the waveforms give the resemblance of enhanced backscatter and movement of the leading edge because the acquisition of S-band waveforms is governed by the $\mathrm{K}_{\mathrm{u}}$-band response. The choice of an attenuation threshold for reliable rain flagging remains to be optimised; because of the variation in sensitivity with wind speed. Clearly a constant threshold of, say, $-0.5 \mathrm{~dB}$ is not appropriate; however, the probability distributions in Fig. 3 show that a simple multiple of the std. dev. does not entirely reflect the change in the underlying distributions.

A simple threshold may not be the answer. Investigators studying global precipitation have a requirement that only genuine rain events are recorded, and those when detection is uncertain are ignored. On the other hand, users concerned solely with large-scale averages of sea surface height may accept the flagging of $20 \%$ of data, if there is an assurance that what remains is totally free of contamination. A solution appears to be the development of a probabilistic rain flag, allowing the individual to set their editing criterion according to a 'likelihood of rain'.

\section{ACKNOWLEDGMENTS}

This study used data provided to the RA2/MWR CrossCalibration Validation Team by CLS, with additional waveform data disseminated by Jerome Benveniste (ESA).

\section{REFERENCES}

[1] T. H. Guymer, G. D. Quartly, and M. A. Srokosz, "The effects of rain on ERS-1 radar altimeter data" J. Atmos. Oceanic. Technol., vol. 12, pp. 1229-1247, 1995.

[2] G. D. Quartly, T. H. Guymer, and M. A. Srokosz, "The effects of rain on Topex radar altimeter data" J. Atmos. Oceanic. Technol., vol. 13, pp. 1209-1229, 1996.

[3] J. Tournadre, and J. C. Morland, "The effects of rain on Topex/Poseidon altimeter data" IEEE Trans. Geosci. and Remote. Sens., vol. 35, pp. $1117-1135,1997$.

[4] G. D. Quartly, M. A. Srokosz, and T. H. Guymer, "Global precipitation statistics from dual-frequency TOPEX altimetry" J. Geophys. Res., vol. 104, pp. 31489-31516, 1999.

[5] A. C. McMillan, G. D. Quartly, M. A. Srokosz, and J. Tournadre, "Validation of the TOPEX rain algorithm: Comparison with groundbased radar" J. Geophys. Res., vol. 107 (D4), pp. 3.1-3.10, 2002.

[6] J. Tournadre, "Determination of rain cell characteristics from the analysis of TOPEX altimeter waveforms" J. Atmos. Oceanic. Technol., vol. 15, pp. 387-406, 1998.

[7] G. D. Quartly, "Determination of oceanic rain rate and rai cell structure from altimeter waveform data. Part I. Theory" J. Atmos. Oceanic. Technol., vol. 15, pp. 1361-1378, 1998. 